according to parishes and contains lists of the Pre-reformation clergy with notes on their lives, as well as much of interest. This volume contains more than 100 illustrations and costs $21 /-$ net. It is a matter for regret that Dr. Wilson did not live to see his work in print. We hope that there will be a large demand for it. The second volume is being prepared for publication.

Royal Medical

IN the hope of obtaining the direct support Benevolent Fund of every practitioner, the Fund is issuing a Five Shilling Appeal

to 21,000 members of the profession in England, Scotland and Wales who have not responded to the Centenary Appeal made in April, 1936. If all who receive the appeal will sign a Banker's Order for only $5 /-$, the income of the Fund will be increased by $£ 5,250$ a year, a sum which is very urgently needed.

Please help to make this appeal a success.

11. Chandos Street,

Cavendish Square,

LONDON, W.1

THIS year is 50th anniversary of foundation of

Société française

La Société française d'ophtalmologie. The d'ophtalmologie

International Society for Prevention of Blindness and the International Council of Ophthalmology hold sittings during the Congress. English members will be very welcome. Further information as to membership can be obtained from Mr. MacCallan, 33, Welbeck Street, W.1.

IN the March number of this Journal, p. 154,

Corrigendum the last two sentences, we regret the omission of a line of print. The termination of the last sentence but one and the beginning of the last sentence should read thus:- . . . being due rather to upgrowth of surrounding parts than to actual epithelial penetration. The paper is profusely illustrated with excellent microphotographs and drawings ....

\title{
FUTURE ARRANGEMENTS
}

\section{7}

April 9.- North of England Ophthalmological Society, at Sheffield. April 16.-Midland Ophthalmological Society, at the Nottingham Eye Infirmary. 